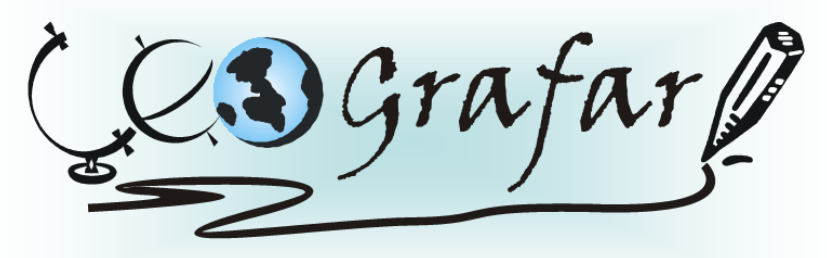

Revista Eletrônica do Programa de Pós-Graduação em Geografia - UFPR

\title{
A ECLOSÃO DE TENSÕES AMBIENTAIS NO ESTADO DO RIO DE JANEIRO. 0 EXEMPLO DA AGENDA 21 COMPERJ NO MUNICÍPIO DE SÃO GONÇALO.
}

\author{
LUIS GUILHERME ALMEIDA BANDEIRA DE MENEZES ${ }^{1}$
}

\begin{abstract}
Resumo: O presente artigo visa discutir acerca das questões ligadas ao meio ambiente. Questões essas que se impõem a partir do processo de transformação do espaço-local, fruto de esferas de poder mais amplas que organizam o espaço-mundo. Trataremos da crise ambiental, em um âmbito geral, e de um estudo de caso da Agenda 21 do Complexo Petroquímico do Estado do Rio de Janeiro (Comperj) em particular. A Eco-92 realizada no Rio de Janeiro consagrou o desenvolvimento sustentável e construiu a Agenda 21, um programa de ação que incentiva soluções locais para a conservação do meio e o desenvolvimento econômico. A Petrobrás utiliza-se desse sistema de modo a garantir legitimidade ao gigantesco empreendimento orçado inicialmente em 8,4 bilhões de dólares e que prevê impactos sócio-ambientais de dimensões diretamente proporcionais. A geografia que se desenha para a região nos próximos anos merece um olhar mais atento que analise os conflitos ambientais que se estabelecem. Para isso esse trabalho entrevistou líderes de associações, de comunidades e de movimentos sociais organizados do município de São Gonçalo que participam ativamente das reuniões da Agenda 21 Comperj, ouvindo suas críticas, reivindicações e contribuições para o projeto. $\mathrm{O}$ artigo vem contribuir, primeiro, com um esforço reflexivo para perspectivas mais ecológicas ao tentar, através da filosofia da ciência, mostrar a insuficiência do paradigma tradicional em responder aos problemas ambientais atuais. Posteriormente objetiva, a partir dos depoimentos dos diversos atores envolvidos, cooperar com uma visão de meio ambiente mais inteligível, onde a sociedade civil possa participar efetivamente da elaboração de políticas públicas mais eficientes e democráticas a fim de construir uma sociedade mais justa.
\end{abstract}

Palavras-chave: Ecologia Política, Conflitos Territoriais, Movimentos Sociais.

\section{THE EMERGENCE OF ENVIRONMENTAL TENSIONS IN THE STATE OF RIO DE JANEIRO. THE EXAMPLE OF AGENDA 21 COMPERJ IN THE MUNICIPAL DISTRICT OF SÃO GONÇALO.}

\begin{abstract}
This article aims to discuss on issues related to the environment. Issues which are needed from the transformation process space-local, result of wider spheres of power that organize the space-world. We treat the environmental crisis in a general context, and a case study of Agenda 21 of the Petrochemical Complex of the State of Rio de Janeiro (Comperj) in particular. The Eco-92 held in Rio de Janeiro has built sustainable development and Agenda 21, a program of action that encourages local solutions to conservation of the environment and economic development. The Petrobrás Company is using that system to ensure legitimacy to the magnificent venture, initially budgeted at 8.4 billion dollars and providing social and environmental impacts of dimensions directly proportional. The geography that is taking shape for the region in the coming years deserves a closer look to examine the environmental conflicts that are established. For that, this work interviewed leaders of associations, leaders of communities and social movements organized of the Sao Goncalo city that are actively participating in the meetings
\end{abstract}

\footnotetext{
${ }^{1}$ Mestrando do Programa de Pós-Graduação em Geografia da Universidade Federal Fluminense. Bolsista CAPES. Email: guigeouff@hotmail.com
} 
of Agenda 21 Comperj, listening to their claims, demands and contributions to the project. The article will contribute, first, with a reflexive effort to more ecological perspective to try, through the philosophy of science, showing the inadequacy of the traditional paradigm in responding to environmental problems today. Later wants, from the testimonies of various actors involved, to cooperate with a vision of the environment more intelligible, where civil society can participate effectively in public policy-making more efficient and democratic in order to build a fairer society.

Keywords: “Green” Policy, Territorial Conflicts, Social Movements.

\title{
INTRODUÇÃO
}

A perspectiva de uma crise ambiental, veiculada pela mídia em tom sensacionalista, é fruto de uma crise de visão de mundo, segundo ecopolíticos como Capra (1982).

As visões controversas acerca da questão do meio ambiente acabam criando contradições que inviabilizam a resolução de problemas a ele relacionados, pois dificultam a construção de um caminho concreto e seguro.

A abordagem ambiental deveria ser então, compreensiva, no sentido de articular as diferentes idéias envolvidas no debate. Milton Santos demonstra essa preocupação quando diz que:

\begin{abstract}
"A idéia de ciência, a idéia de tecnologia e a idéia de mercado global devem ser encaradas conjuntamente e desse modo podem oferecer uma nova interpretação à questão ecológica, já que as mudanças que ocorrem na natureza também se subordinam a essa lógica". (SANTOS, 2004, p. 238).
\end{abstract}

O Fórum Econômico Mundial, que ocorre em Davos na Suíça, reúne representantes de governos e grandes empresários com o objetivo de elaborar as diretrizes econômicas para o ano em vigor. Nos últimos anos o meio ambiente veio sendo abordado com maior freqüência devido às alterações do clima global e, principalmente, ao desafio econômico que isso representa o que vem fazendo surgir uma visão "eco-mercado-lógica", como a expressada por Fernando Almeida, presidente-executivo do Conselho Empresarial Brasileiro para o Desenvolvimento Sustentável (CEBDS), em seu livro intitulado O Bom Negócio da Sustentabilidade:

“... desenvolvimento sustentável é um sistema de mercados abertos e competitivos em que os preços refletem com as transparências dos custos, inclusive os ambientais. Se os 
preços são fixados adequadamente, sem estarem, por exemplo, mascarados por subsídios e políticas protecionistas, a competição estimula os produtores a usar o mínimo de recursos, reduzindo o avanço sobre os sistemas naturais. Também os estimula a minimizar a poluição, se são obrigados a pagar pelo seu controle e pelos danos causados ao meio ambiente". (ALMEIDA, 2002).

Paralelo a este, acontece o Fórum Social Mundial (FSM) com o lema de que "Um Outro Mundo é Possível". O FSM surge da necessidade de debater a sociedade e seus desdobramentos culturais, políticos e ambientais propondo alternativas ao processo de globalização neoliberal. Por reunir ONGs, movimentos sociais e intelectuais de diversas partes do mundo, trata-se de um fórum mais plural, onde a questão ambiental ganha significados distintos. O movimento ecológico não possui um condicionante social que o justifique, uma vez que não existe um corpo ecológico enquanto base objetiva ${ }^{2}$, dessa forma a luta ambiental não define um movimento com uma agenda própria, mas está inserida transversalmente nas pautas de reivindicações dos diversos movimentos.

Ao contrário da pluralidade de visões que se inter-relacionem, o que vem sendo observado são posturas antagônicas acerca da relação homem/meio. As mais "românticas", segundo Moraes (1997, p.55) estão expressas ambientalmente no "preservacionismo radical, que no limite, pode veicular perspectivas anti-humanísticas ao colocar a natureza como um valor maior que o homem" (p.55). No outro extremo encontram-se tentativas de reificação do meio ambiente, onde a natureza é dessacralizada podendo ser usufruída de forma indiscriminada.

Pretendemos com esse trabalho destacar a necessidade de se promover novas formas de entendimento do meio que possam dialogar tanto com o campo acadêmico, quanto com o senso comum, de modo a tecermos políticas públicas realmente sustentáveis. Nesse sentido discutiremos sobre o embate travado no Fórum da Agenda 21 Comperj do município de São Gonçalo-RJ, cidade de quase um milhão de habitantes ${ }^{3}$ situada na Região Metropolitana do Rio de Janeiro (RMRJ) e que possui como municípios limítrofes Niterói, Maricá e Itaboraí, este último, local de construção do Comperj.

Esse artigo se dividirá em quatro partes. A primeira parte apresentará a percepção do meio ambiente que permeia o cenário científico desde o início do discurso ambiental, tentando

\footnotetext{
${ }^{2}$ PORTO-GONÇALVES, 1996, p.21

${ }^{3}$ Fonte: Contagem de população. IBGE, 2007.
} 
des(re)construí-la a partir de uma análise epistemológica. A segunda trata de assinalar as premissas sócio-ambientais para uma possível mudança de paradigma decorrente de conflitos territoriais e simbólicos resultados do esgotamento de um modelo de desenvolvimento. A terceira parte visa refletir sobre o sistema de Agenda 21 Global, problematizando o conceito de desenvolvimento sustentável. A última parte analisa a Agenda 21 Comperj, seus possíveis impactos sócio-ambientais e abre um diálogo com os movimentos sociais do município de São Gonçalo, para que contribuam na elaboração de novas perspectivas.

\section{DA PERSPECTIVA DE CRISE A CRISE DE PERSPECTIVA: ALGUMAS NOTAS EPISTEMOLÓGICAS}

A raiz da ecologia está, para muitos, em Haeckel e sua filosofia monista, que se contrapôs ao dualismo cartesiano. Enquanto Descartes afirmava uma separação da res cogitans e da res extensa inaugurando uma visão mecânica do mundo no século XVII, Haeckel propôs uma compreensão orgânica do mesmo já no século XIX. ${ }^{4}$

O racionalismo cartesiano foi um dos grandes responsáveis pela dicotomização homem/meio, onde o último passa a poder ser livremente apropriado material ou simbolicamente pelo primeiro. Para Moreira (1987), trata-se na verdade de uma tricotomia Natureza-HomemEspaço (N-H-E) que dificulta uma análise mais profunda dos fatos, pois nas ciências e, sobretudo na Geografia o estudo da realidade aparece aos cacos.

Com a manutenção dessas separações, os fenômenos naturais passam a ser mensurados e compreendidos através de uma matriz matemática do pensamento. Para Harvey, durante a modernidade esse "domínio científico da natureza prometia liberdade da escassez, da necessidade e da arbitrariedade das calamidades naturais" (1996, p. 23).

Outro êxito de Descartes foi o de criar um modelo de funcionamento do homem e da natureza como uma máquina. Essa visão reducionista permitiu uma fragmentação da realidade para um melhor aprofundamento analítico, ou seja, surge daí as especializações das ciências. O método cartesiano foi complementado por Newton e a física passa a se tornar à base de todo o

\footnotetext{
${ }^{4}$ CHALMERS, 1993.
} 
pensamento científico. Era inaugurada nesse momento a separação espaço/tempo onde emerge a idéia de imutabilidade do espaço, muito antes do nascimento da geografia como ciência, pois já em Newton "o espaço absoluto, em sua própria natureza, sem levar em conta qualquer coisa que lhe seja externa, permanece sempre inalterado e imóvel" 5 e o tempo "flui uniformemente, sem depender de qualquer coisa externa" 6 .

O conjunto de teorias baseadas no método científico racional estabelece um paradigma cartesiano-newtoniano ${ }^{7}$ que se legitima universal e que crê numa progressão linear e cumulativa das ciências.

O sucesso desse paradigma em responder as questões que surgiram, fizeram com que ele fosse poucas vezes questionado. Para Thomas Kuhn (1987) uma crise paradigmática só se estabelece no momento em que a ciência normal (a que se desenvolveu sobre um paradigma dominante) não consegue mais responder aos problemas que se impõem. A elaboração de uma ciência revolucionária, afastada dos antigos paradigmas, constituirá um novo quando for suficientemente aceita por uma comunidade científica (p.271). Kuhn não crê então num avanço linear, mas num avanço por rupturas.

Fritjof Capra (1982) traz a filosofia oriental para a discussão dos paradigmas, e anuncia um ponto de mutação ${ }^{8}$ localizado em três crises. A crise do esgotamento dos combustíveis fósseis, a crise da sociedade patriarcal e a crise de idéias e valores (p.27-28). Para o autor vivemos um período de transição de paradigma que é expresso, por exemplo, na insuficiência do modelo cartesiano em prever e/ou resolver os problemas das alterações climáticas, aumento da desertificação, poluição dos rios e solos etc. O autor chama a atenção para a debilidade da noção de progresso ocidental onde ocorre uma superposição de valores yang ${ }^{9}$, ou seja, ações ligadas à competitividade, centradas no "eu” (“ego-ações”), sobre valores yin, ações ligadas à cooperação, conscientes do meio ambiente ("eco-ações”) (p.35). Esses dois pólos devem buscar um equilíbrio, pois quando um se sobrepõe ao outro acabam por caracterizar uma crise como a experimentada hoje.

\footnotetext{
${ }^{5}$ NEWTON Apud CAPRA, 1982, p.60

${ }^{6}$ Id., ibid.

${ }^{7}$ Paradigma entendido por Kuhn (1987) como uma estrutura teórica convencionada por um grupo científico.

${ }^{8}$ Em seu livro homônimo.

9 "Yin" e "yang" são conceitos do livro chinês I-Ching.
} 
É indispensável que haja uma mudança de valores que passe por uma percepção do meio ambiente. Emerge daí a visão ecológica.

No início do século XX a ciência monista de Haeckel, calcada no evolucionismo de Darwin e no positivismo de Comte, tenta compreender a natureza como um todo, onde cada parte desempenha seu papel "naturalmente" estipulado. Essa postura veio a justificar, em parte, a sociedade de classes ao corroborar com uma visão positiva das relações sociais com suas estratificações “inerentes”, porém rompe com a máquina do mundo newtoniana ao estabelecer uma relação homem/meio “orgânica”. (CHALMERS, 1993).

Haeckel, por sua vez, influenciou Ratzel e o seu conceito de "espaço vital” caracterizado como aquele em que são delimitadas as "necessidades territoriais de uma sociedade em função de seu desenvolvimento tecnológico, do total de população e dos recursos naturais" (CORREA, 1995, p.18). O esforço de Ratzel em ecologizar as relações sócio-territoriais é reconhecido até mesmo por outras escolas da Geografia. La Blache comenta as obras do alemão dizendo que este conseguiu uma "conjunção das ciências naturais e das ciências do homem"10.

A idéia de natureza herdada de Haeckel se apresenta então sob uma nova forma de reducionismo, dessa vez, como sinônimo de "recursos naturais", podendo ser livremente apropriada uma vez que sua função é a de servir ao homem.

As condições para uma transição paradigmática, que ultrapasse um modelo tradicional de entendimento do meio ambiente, não se limitam às circunstâncias científicas, pois elas, em si, podem forjar um progresso sob um paradigma já vigente. Para Boaventura de Souza Santos (2000) tem de haver um condicionante político e social que permita recuperar pensamentos "vulgares, marginais, subculturais" (p.36) que se desenhavam no paradigma anterior, agora em crise.

Portanto a crise ambiental se impõe como um obstáculo epistemológico ${ }^{11}$ onde se faz necessária uma dupla ruptura epistemológica ${ }^{12}$ para a condução de novos métodos, novas técnicas e novas teorias.

\footnotetext{
10 Apud DOMINGUES (1985, p.118)

${ }^{11}$ BACHELARD apud SANTOS, Boaventura de S. (2000, p. 42)

${ }^{12}$ Pois segundo Boaventura de S. Santos “os obstáculos epistemológicos se apresentam sempre aos pares” (p. 41).
} 
“... a dupla ruptura procede a um trabalho de transformação tanto do senso comum como da ciência. Enquanto a primeira ruptura é imprescindível para constituir a ciência, mas deixa o senso comum tal como estava antes dela, a segunda ruptura transforma o senso comum com base na ciência. Com essa dupla transformação pretende-se um senso comum esclarecido e uma ciência prudente..." (p. 41)

A trajetória da ciência normal para uma ciência pós-moderna passa pelo esforço da reflexão hermenêutica e da desdogmatização científica. Nesse movimento é confrontada a idéia una do real e "o que se pretende é um novo senso comum com mais sentido". (SANTOS, B. S., 2000, p. 150).

\section{COLABORAÇÕES PARA A CONSTRUÇÃO DO "SABER AMBIENTAL"}

A partir da análise da evolução científica demonstrada anteriormente, percebe-se o esgotamento do paradigma em questão que vem se mostrando rígido e mecânico. Nesse sentido é essencial uma proposição que o substitua, que seja mais flexível e ao mesmo tempo holística.

Desse modo autores, como Enrique Leff, buscam ultrapassar os limites cientificistas e categoriza a epistemologia ambiental como

“... parte do esforço por pensar a articulação de ciências capazes de gerar um método e um pensamento integrador do real, para desembocar num saber que vai além do conhecimento científico, para problematizar a racionalidade modernizadora que provoca a crise ambiental” (LEFF, 2006, p.17-18).

$\mathrm{O}$ autor afirma a necessidade de construir uma racionalidade ambiental que contraponha a racionalidade produtiva, e para isso, a condição básica seria estabelecer uma interdisciplinaridade do saber científico. Santos (2006) corrobora com a idéia de promover um diálogo entre as múltiplas visões quando afirma que:

"A denominada crise ambiental a que hoje assistimos padece dessa situação e deve suscitar uma revisão das teorias e práticas das diversas disciplinas na medida em que 
demanda uma análise compreensiva, totalizante ${ }^{13}$, uma análise na qual as pessoas, vindas de horizontes diversos e que trabalhem com a realidade presente, tenham o seu passo acertado através do mundo, através de um legítimo trabalho interdisciplinar".

A (re)valorização da compreensão interdisciplinar nas ciências deve-se, também, as grandes questões levantadas pelos problemas ambientais e ao esforço de tentar solucioná-los. Não se trata de integrar visões contraditórias, que nada contribuiriam para o avanço do saber ambiental, mas de articular visões de diferentes escalas, ainda que conflitantes, mas que dialoguem entre si e configurem para além de si um "paradigma plural”.

Pretendemos então perceber o conflito, em suas mais diversas escalas, como produtor de novos entendimentos da realidade. Na educação, autores como Mugny \& Doise (1983) sustentam que a interação do sujeito com diferentes discursos produz um conflito sócio-cognitivo que estabelece um verdadeiro progresso do pensamento. A produção de um pensar ecológico pode ser viabilizada no embate desses diferentes discursos, numa tentativa de tornar o meio que nos cerca mais inteligível.

Uma segunda proposta de Leff consiste em "internalizar as bases ecológicas e os princípios jurídicos e sociais para a gestão democrática dos recursos naturais" (2006 p.59). Nesse sentido, propostas como a Rede Brasileira de Justiça Ambiental (RBJA) conseguiram reunir diversas ONG's, movimentos sociais, sindicatos e pesquisadores do Brasil para tecer um manifesto em prol da justiça ambiental. Constatou-se que a maior parte dos impactos ambientais como contaminação de água potável, áreas com ar poluído, proximidades de depósitos de lixo tóxico etc., encontravam-se nos arredores de áreas que já eram segregadas socialmente. Os bolsões de pobreza também são injustiçados ambientalmente. $\mathrm{O}$ manifesto prega um conjunto de medidas e práticas que:

\footnotetext{
"a- asseguram que nenhum grupo social, seja ele étnico, racial ou de classe, suporte uma parcela desproporcional das consequiências ambientais negativas de operações econômicas, de decisões de políticas e de programas federais, estaduais, locais, assim como da ausência ou omissão de tais políticas;

b- asseguram acesso justo e eqüitativo, direto e indireto, aos recursos ambientais do país;
}

\footnotetext{
${ }^{13} \mathrm{O}$ autor afirma uma visão "totalizante" que busque a compreensão do todo a partir de um entendimento das partes e a diferencia de uma visão "totalista" que se quer universal, padrão.
} 
c- asseguram amplo acesso às informações relevantes sobre o uso dos recursos ambientais e a destinação de rejeitos e localização de fontes de riscos ambientais, bem como processos democráticos e participativos na definição de políticas, planos, programas e projetos que lhes dizem respeito;

d- favorecem a constituição de sujeitos coletivos de direitos, movimentos sociais e organizações populares para serem protagonistas na construção de modelos alternativos de desenvolvimento, que assegurem a democratização do acesso aos recursos ambientais e a sustentabilidade do seu uso."14

\section{A AGENDA 21 E O DESENVOLVIMENTO (IN)SUSTENTÁVEL}

A construção do Comperj insere-se, em parte, numa antiga lógica enraizada no racionalismo científico e na liberdade burguesa que justificaram o projeto de modernidade. Para Porto-Gonçalves a "invenção do europeu civilizado é, ao mesmo tempo, a invenção do selvagem e, assim, a invenção da modernidade é inseparável da invenção da colonialidade” (2001, p. 2). Desse modo, falamos aqui de um mundo "moderno-colonial" dialeticamente construído e que, numa evolução histórico-linear, estabelece hoje uma (des)ordem "desenvolvidosubdesenvolvido".

O processo de superação dos padrões modernos de interpretação do meio ambiente já foi iniciado, o problema está em dizer se ele irá convergir para reais transformações das condições sócio-ambientais, ou se para adaptações dos novos padrões técnicos aos antigos modelos de exploração.

Em Estocolmo-72, na Primeira Conferência das Nações Unidas sobre Meio Ambiente e Desenvolvimento, a humanidade reconhece pela primeira vez o poder de intervenção do homem como algo maior que um simples "fator antrópico" e anuncia a possibilidade de mudanças no arquétipo de desenvolvimento. Em 1987 o Relatório Brundtland cria o “desenvolvimento sustentável" como àquele que satisfaz as necessidades presentes sem comprometer a capacidade das gerações futuras de suprir as suas próprias necessidades. A Eco-92 realizada no Rio de Janeiro consagra o "desenvolvimento sustentável” e constrói a Agenda 21, um programa de ação que incentiva soluções locais para a conservação do meio e o desenvolvimento econômico. A Agenda 21 representa um avanço aparente nas questões da democracia participativa, pois chama a sociedade civil para o debate e a construção de um modelo sustentável, porém esbarra nas

\footnotetext{
${ }^{14}$ Trecho do Manifesto da Rede Brasileira de Justiça Ambiental publicado em 2001.
} 
forças de mercado que a cercam. Em uma rápida leitura da Seção I, capítulo 2, da Agenda 21 Global podemos perceber algumas dessas limitações para as políticas direcionadas aos países em desenvolvimento:

“2.3. Cabe à economia internacional oferecer um clima internacional propício à realização das metas relativas a meio ambiente e desenvolvimento, das seguintes maneiras: comércio;

(a) Promoção do desenvolvimento sustentável por meio da liberalização do

(b) Estabelecimento de um apoio recíproco entre comércio e meio ambiente;

(c) Oferta de recursos financeiros suficientes aos países em desenvolvimento e iniciativas concretas diante do problema da dívida internacional;

(d) Estímulo a políticas macroeconômicas favoráveis ao meio ambiente e ao desenvolvimento.

2.9. Nos anos vindouros e levando em consideração os resultados da Rodada Uruguai de negociações comerciais multilaterais, os Governos devem continuar a empenhar-se para alcançar os seguintes objetivos:

(a) Promover um sistema comercial aberto, não-discriminatório e eqüitativo que possibilite a todos os países, em especial aos países em desenvolvimento, aperfeiçoar suas estruturas econômicas e aperfeiçoar o nível de vida de suas populações por meio do desenvolvimento econômico sustentado.

(b) Aperfeiçoar o acesso aos mercados das exportações dos países em desenvolvimento;

(c) Aperfeiçoar o funcionamento dos mercados de produtos básicos e adotar políticas saudáveis, compatíveis e coerentes, nos planos nacional e internacional, com vistas a otimizar a contribuição do setor dos produtos básicos ao desenvolvimento sustentável, levando em conta considerações ambientais;

(d) Promover e apoiar políticas internas e internacionais que façam o crescimento econômico e a proteção ambiental apoiarem-se mutuamente."

Uma diferença parece muito clara entre os interesses do livre mercado e as reais possibilidades de justiça social e preocupações com o meio ambiente. A maioria dos países em desenvolvimento, em especial na América Latina, tem cumprido a risca as orientações da Agenda 21, no que diz respeito à adoção de "políticas saudáveis", otimização da contribuição no setor de produtos básicos e mesmo o de promover a liberalização do comércio. (ACSELRAD, 2003).

O modelo de desenvolvimento inaugurado na modernidade e universalizado pela globalização neoliberal, agora se quer permanente (sustentável). Porém sua durabilidade é questionável se observarmos a emergência de visões alternativas oriundas dos movimentos sociais, sobretudo nos países periféricos. Nessa linha de pensamento Acselrad e Leroy (2003) dizem que: 
"O desenvolvimento difunde uma temporalidade mercantil sobreposta à multiplicidade de tempos sociais, assim como faz predominar o território competitivo sobre as múltiplas formas da experiência social do espaço. A imposição do tempo do mercado e a configuração do espaço para a acumulação capitalista implicam a resistência dos grupos sociais que fazem do meio ambiente o campo da construção de projetos contrahegemônicos de desenvolvimento, com horizontes temporais e trajetórias históricas próprias".(p.25)

Os mesmo autores ainda ressaltam o esforço feito por órgãos reguladores nacionais e internacionais para forjar um nivelamento de grupos sociais pertencentes a classes distintas. Por exemplo, a diferença do volume extraído de madeira de uma determinada comunidade campesina, comparado a das grandes madeireiras, assim como seus diferentes usos são visíveis, porém há um forte discurso na tentativa de equiparar os danos ambientais de ambos.

A (des)ordem global e as noções dominantes de sustentabilidade já nascem condenadas, pois enquanto a primeira acirra as contradições sociais inerentes ao capitalismo neoliberal, a segunda trata de ratificar uma "mudança conservadora", pontual, sem que hajam transformações estruturais.

\section{A AGENDA 21 COMPERJ A PARTIR DO $4^{\circ}$ SETOR DO MUNICÍPIO DE SÃO GONÇALO}

A construção do Comperj no norte do município de Itaboraí já se iniciou ${ }^{15}$ independente das discussões dos Fóruns de Agenda 21 Locais, construídas nos 15 municípios participantes do projeto. O sistema de Agenda 21 apresenta uma clara disputa de interesses, a começar pela divisão dos debates por setores. No $1^{\circ}$ setor estão os membros de órgãos públicos, o $2^{\circ}$ setor engloba empresários, industriais e comerciantes, no $3^{\circ}$ setor participam representantes de ONGs, sindicatos, associações de classe e fundações, enquanto o $4^{\circ}$ setor é o da representação dos movimentos sociais, de membros da sociedade civil organizada e de associações de moradores. Através de licitações o poder público selecionou ONGs executoras dos Fóruns de Agenda 21 para cada setor. Foram vencedoras o Instituto Ipanema ( $1^{\circ}$. setor); o ISER ( $2^{\circ}$ setor); a Roda Viva ( $3^{\circ}$ setor) e a $\operatorname{ASA}\left(4^{\circ}\right.$ setor $)$.

\footnotetext{
${ }^{15}$ A obra de terraplanagem foi iniciada no dia 31 de março de 2008.
} 
O sistema de Agenda 21 prevê Fóruns Municipais de caráter deliberativo para elaborar planos de desenvolvimento locais. Nestes são eleitos quatro delegados (um de cada setor) que representarão os municípios no Fórum Regional da Agenda 21. Desta maneira se forja a representatividade da sociedade civil no âmbito das decisões da agenda. O problema vai além da pseudoparidade, pois também passa pelo próprio entendimento da categoria "comunidade" como um todo homogêneo.

A Associação de Serviços Ambientais (ASA) que gerencia o $4^{\circ}$ setor ressalta a importância dos presentes trazerem consigo mais pessoas para uma "construção coletiva e democrática" da Agenda 21. Porém na opinião de Afonso Sobrinho ${ }^{16}$ (representante da Associação de Pescadores da Praia de São Gabriel em Itaoca, São Gonçalo) "a Agenda 21 do Comperj é uma forma que a empresa Petrobrás encontrou de legitimar o seu empreendimento". O pescador ainda denuncia que:

"A Petrobrás fez de que iria ter um empreendimento de oito bilhões de dólares aqui na região. Portanto, a partir desse anúncio, todas as pessoas passaram a entender, o grosso da população passou a achar, que teria um emprego, que seus filhos teriam um emprego, que conseguiriam um espaço dentro do Comperj e isso não é verdade".

A preocupação de Afonso Sobrinho justifica-se na medida em que o próprio poder municipal de São Gonçalo cria todo um imaginário da esperança de prosperidade e emprego.

O município tem o $2^{\circ}$ maior colégio eleitoral do Estado com cerca de 635 mil pessoas e ao mesmo tempo foi o que mais recebeu promessas de geração de empregos por parte do Governo do Estado. Possui uma tradicional economia industrial, tendo participação importante na economia do estado durante as décadas de 40 e 50, com fábricas metalúrgicas, químicas, farmacêuticas e de papel, chegando a ser apelidada de "Manchester Fluminense" em referência a cidade inglesa de grande concentração industrial. Nos últimos anos a cidade vem recebendo fábricas que estão fugindo do município do Rio, em busca de incentivos fiscais, mão-de-obra

\footnotetext{
${ }^{16}$ Para esse trabalho foram entrevistados três membros do $4^{\circ}$ setor da Agenda 21 do município de São Gonçalo.
} 
barata e infra-estrutura urbana equipada. É o que ocorreu com a Gerdau e a CCPL, para citar exemplos $^{17}$.

\section{FIGURA 1: FOTO DE PLACA EM FRENTE À PREFEITURA DE SÃO GONÇALO, COM REFERÊNCIA AO COMPERJ}

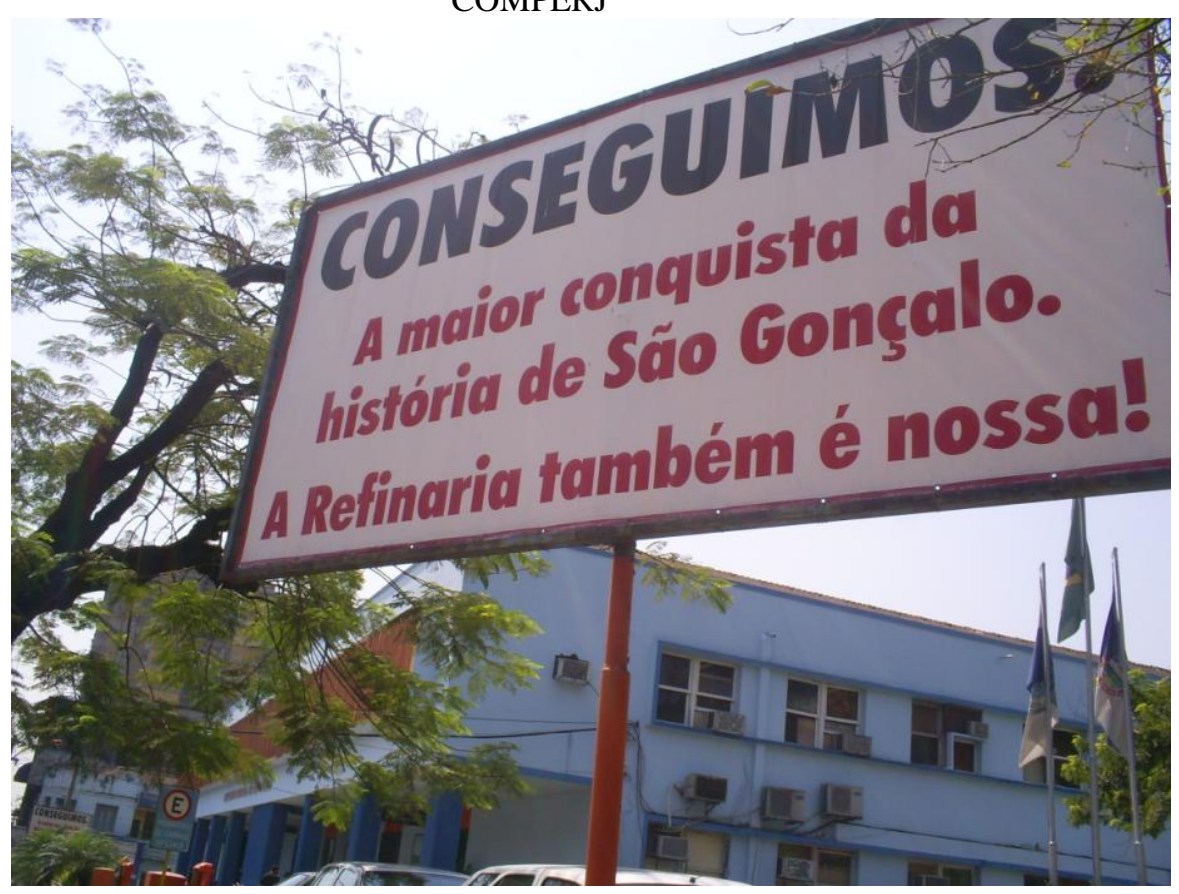

Com a promessa de geração de mais de 200 mil empregos ${ }^{18}$, o Comperj já provoca uma economia de aglomeração na região, justificando a lógica da urbanização corporativa ${ }^{19}$ à que Santos (2005) nos chama atenção, porém, agora apresentada sob o discurso da "sustentabilidade". Sabe-se, no entanto, que apenas uma pequena parcela dessa mão-de-obra desempregada (78.156 habitantes, ou 8,77\% da População Economicamente Ativa do município ${ }^{20}$ ) será absorvida pelo mercado de trabalho formal após a conclusão das obras.

O projeto prevê também a construção de um arco rodoviário de $145 \mathrm{~km}$ estimado em 800 milhões de reais, onde serão utilizados recursos do PAC. A obra vai construir um trecho de 72

\footnotetext{
${ }^{17}$ Fonte: Prefeitura Municipal de São Gonçalo.

${ }^{18}$ Fonte: RIMA do Complexo Petroquímico do Estado do Rio de Janeiro.

${ }^{19}$ Onde "o essencial do esforço de equipamento é primordialmente feito para o serviço das empresas hegemônicas; o que porventura interessa às demais empresas", enquanto opõe "parcelas da cidade, frações da população, formas concretas de produção, modos de vida, comportamentos".(p.122)

${ }^{20}$ Fonte: CENSO/2000 - IBGE. Elaboração MTE.
} 
km entre os municípios de Duque de Caxias, onde se localiza a Reduc (Refinaria de Duque de Caxias) e Itaguaí (onde se situa o Porto de Sepetiba). Além de duplicar os outros $73 \mathrm{~km}$ até o município de Itaboraí, local do Comperj.

Os impactos ambientais calculados são enormes, porém são minimizados a todo o momento, junto ao discurso da geração de empregos e da elaboração de um "corredor ecológico". A concepção conservacionista, que toma conta do ambientalismo liberal, prega a segregação de comunidades tradicionais em áreas delimitadas. Observa-se aí, a mesma noção de propriedade privada, que não faz parte da episteme de muitas comunidades. A existência de comunidades tradicionais dentro de áreas protegidas pode ser um empecilho para muitos preservacionistas, que se utilizam do aparelho do estado para a retirada desses grupos, porém o mesmo aparelho estatal serve aos interesses do capital na elaboração de projetos industriais, como o do Comperj.

A Agenda 21 propaga a idéia do consenso como condição fundamental para tornar o desenvolvimento sustentável possível (ACSELRAD et al, 2006), mas ao dar suporte a um modelo de sociedade excludente acaba gerando conflitos.

O mais grave episódio da história recente da Petrobrás ocorreu em Janeiro de 2000, quando um acidente causado pelo derramamento de 1,3 milhão de litros de óleo combustível na Baía de Guanabara prejudicou a pesca por vários meses e destruiu parte dos mangues da região ${ }^{21}$. A FEEMA (Fundação Estadual de Engenharia do Ambiente - RJ) sequer cogitou o fechamento da REDUC, pois esta representava uma grande fonte de renda para o Estado. A impunidade ambiental por parte de diversas empresas só fez crescer as tensões entre estas e os moradores de todo o estado e em especial do município de São Gonçalo.

As distintas formas de perceber e de se relacionar com o meio resultam em conflitos onde observamos assimetrias de poderes entre os grupos envolvidos. Enquanto os três primeiros setores se utilizam dessa aparelhagem estatal e da Agenda 21 para territorializarem áreas de interesse funcional, os atores do $4^{\circ}$ setor disputam um território mínimo, nas palavras de Haesbaert (2004).

\footnotetext{
${ }^{21}$ Informações e mapa adaptados do CD-ROM: Mapa dos Conflitos Ambientais no Estado do Rio de Janeiro, 2006. Neste foram recolhidas informações de conflitos relacionados ao meio ambiente entre os anos de 1992 a 2005.
} 
O mesmo autor nos chama atenção para a importância de olharmos para esses grupos menos favorecidos, pois:

“... enquanto uma elite globalizada tem a opção de escolher entre os territórios que melhor lhe aprouver, vivenciando efetivamente uma multiterritorialidade, outros, na base da pirâmide social, não têm sequer a opção do 'primeiro' território, o território como abrigo, fundamento mínimo de sua reprodução física cotidiana”. (p. 360).

O abrigo, a morada, o oikos, que vem sendo negado pelos poderes hegemônicos aos que necessitam do território mínimo, também configuram um problema ecológico em seu sentido lato. Daí podem decorrer conflitos territoriais motivados por descaso com o meio ambiente por grande parte de empresas e/ou por negligência do Estado, como o que podemos observar na figura 2 .

\section{FIGURA 2: TENSÕES AMBIENTAIS NOS MUNICÍPIOS ENVOLVIDOS NO COMPERJ. ADAPTADO DE MAPA DOS CONFLITOS AMBIENTAIS NO ESTADO DO RIO DE JANEIRO, CDROM, 2006.}

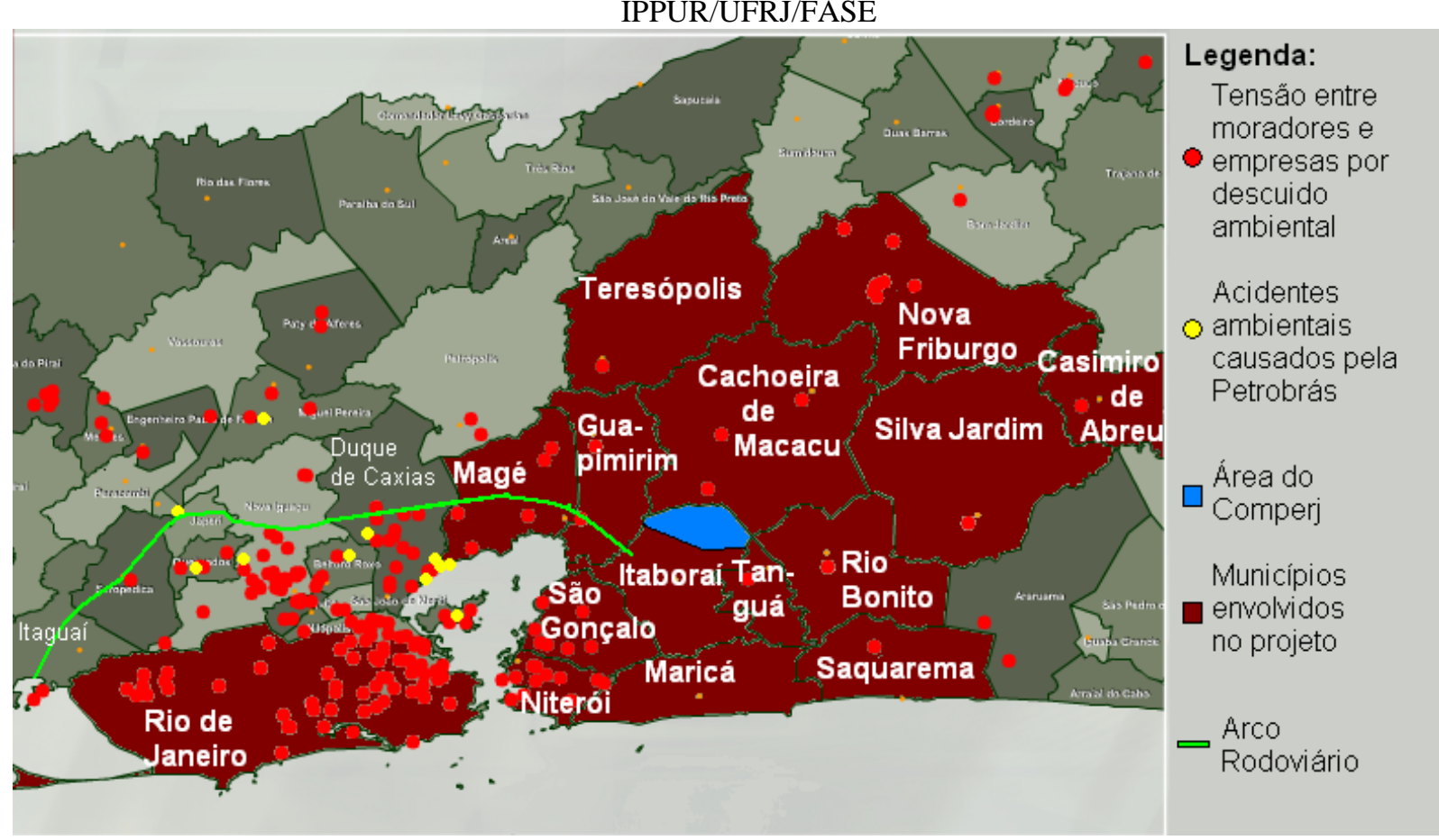


De um total de 480 conflitos ambientais ocorridos entre 1992 e 2005 no Estado do Rio de Janeiro 306 deles envolvem uma participação direta dos moradores, sendo 101 nos municípios abarcados pelo Comperj. 11 casos são de responsabilidade direta da Petrobrás.

\section{CONSIDERAÇÕES FINAIS}

O desafio maior desse trabalho é o de aliar o conhecimento científico ao saber da sociedade civil, para uma visão mais compreensiva do meio ambiente. Entendimentos como o de Maria Lucídia Tavares, presidente da Salvarte, quando expressa que "a medida mais importante que não só a Agenda 21, mas a sociedade deveria tomar para questão do meio ambiente é basicamente Educação. Só através da educação vai se criar uma consciência nas pessoas do dever de preservar". Esses saberes devem complementar as análises científicas de modo a orientar as políticas públicas para a sociedade e o meio ambiente.

O estabelecimento de uma relação harmônica e holística entre homem, natureza e espaço passa também por um equilíbrio nas relações sociais. A manutenção de uma sociedade de classes é, portanto a manutenção da crise ambiental. As novas formas de desenvolvimento que se pregam sustentáveis já nascem condenadas pela carência de uma visão multiculturalista, ao basear-se na ciência moderna e por não questionar as injustiças sócio-ambientais.

A constituição de redes sócio-ambientais que trace projetos alternativos de sustentabilidade é possível, desde que preservados o diálogo da ciência com os saberes tradicionais de modo a nascer uma racionalidade ambiental que pregue como o pescador José Mesquita (presidente da Alpega) um meio ambiente como:

\footnotetext{
“vida, porque como pescador, sem meio ambiente com certeza não terá peixe, e não tendo peixe não terá pescador, essa resposta aparentemente simples eu acho bastante significativa, observando por outro lado eu também penso que na verdade o meio ambiente significa, nós, nós como pessoas, nós como seres, nós como uma entidade, nós como sociedade, se nós tratarmos melhor o meio em que nós atuamos e sobrevivemos com certeza nós estaremos especificamente tratando melhor da nossa própria vida".
} 


\section{REFERÊNCIAS:}

ACSELRAD, Henri; LEROY, Jean-Pierre. Novas premissas de sustentabilidade democrática. Projeto Brasil Sustentável e Democrático. 2ªed. Rio de Janeiro: Fase, 2003.

ACSELRAD, Henri; MELlO, Cecília C. do Amaral; BEZERRA, Gustavo Das Neves. Cidade, Ambiente e Política: Problematizando a Agenda 21 local. Rio de Janeiro: Garamond Universitária, 2006.

ALMEIDA, Fernando. O bom negócio da sustentabilidade. Rio de Janeiro: Nova Fronteira 2002.

CAPRA, Fritjof. O ponto de mutação. São Paulo: Cultrix, 1982.

CHALMERS, Alan F. O que é ciência afinal? : Brasiliense, 1993.

CORREA, Roberto Lobato. Espaço um conceito-chave da geografia. In: CASTRO, Iná Elias de, GOMES, Paulo César da Costa e CORREA, Roberto Lobato (Org.). Geografia: Conceitos $e$ Temas. Rio de Janeiro: Bertrand-Brasil, 1995. p. 15-47.

DOMINGUES, Álvaro A. G.. A geografia regional vidaliana: Enquadramento teóricometodológico e ideológico. In: Revista da Faculdade de Letras-Geografia. Disponível em: <http://ler.letras.up.pt/uploads/ficheiros/artigo3351.pdf>. p. 113-134, mar. 1985. Acesso em: 25 de março de 2008.

HARVEY, David. Condição Pós-Moderna. 6 ed. São Paulo: Loyola, 1996.

HAESBAERT, Rogério. $O$ mito da desterritorialização: do fim dos territórios a multiterritorialidade. Rio de Janeiro: Bertrand-Brasil, 2004.

KUHN, Thomas. A Estrutura das Revoluções Científicas. São Paulo: Perspectiva, 1987.

LEFF, Enrique. Epistemologia ambiental. 4ª ed. São Paulo: Cortez, 2006.

MUGNY, G.; DOISE, W. La Construcción Social de la Inteligencia. México: Editorial Trillas, 1983.

MORAES, Antônio C. R. Meio ambiente e Ciências Humanas. São Paulo: Hucitec, 1997.

MOREIRA, R. O discurso do avesso: Para crítica da geografia que se ensina. Rio de Janeiro: Dois Pontos; 1987. Cap. 1, p.13-35.

PORTO-GONÇALVES, C. W. Os (Des)caminhos do Meio Ambiente. São Paulo: Contexto, 1996.

Da Geografia às Geo-grafias. Texto apresentado na II Conferencia Latinoamericana y Caribeña de Ciencias Sociales. Grupo de Trabajo de Economía Internacional. Universidad de Guadalajara, México, 21-22 de Noviembre de 2001.

SANTOS, Boaventura de S. Introdução a uma ciência pós-moderna. Rio de Janeiro: GRAAL, 2000 . 
SANTOS, Milton. A Natureza do Espaço. $4^{\mathrm{a}}$ ed. São Paulo: Edusp, 2004. . A Urbanização Brasileira. 5a ed. São Paulo: Edusp, 2005.

. A questão do meio ambiente: desafios para a construção de uma perspectiva

transdisciplinar. Revista de Gestão Integrada em Saúde do Trabalho e Meio Ambiente, São Paulo, p.01-14, ago. 2006. Disponível em: $<$ http://www.interfacehs.sp.senac.br/br/traducoes.asp?ed=1\&cod_artigo=12>.

\section{MULTIMÍDIA:}

CONCREMAT Engenharia/PETROBRÁS, RIMA do Complexo Petroquímico do Rio de Janeiro, CDROM, 2007.

IBGE. Contagem de população 2007. Disponível em: 〈www.ibge.gov.br〉. Acesso em: 10 de setembro de 2008.

IPPUR/UFRJ/FASE, Mapa dos Conflitos Ambientais no Estado do Rio de Janeiro, CDROM, 2006.

MINISTÉRIO DO MEIO AMBIENTE. AGENDA 21 Mundial. Disponível em: $<$ http://www.mma.gov.br/index.php?ido=conteudo.monta\&idEstrutura=18\&idConteudo=575>

PREFEITURA DE SÃO GONÇALO. Disponível em: 〈www.saogoncalo.rj.gov.br〉. Acesso em: 27 de outubro de 2008.

REDE BRASILEIRA DE JUSTIÇA AMBIENTAL, Manifesto de lançamento da RBJA, Disponível em: www.justicaambiental.org.br/_justicaambiental/pagina.php?id=229

(Recebido em outubro/08. Aceito em abril/09) 